\title{
Ringer's Lactate Hydration and Incidence of Post ERCP Pancreatitis: A Descriptive Cross-sectional Study
}

\author{
Ashis Pun, ${ }^{1}$ Amit Dhungana, ${ }^{2}$ Dipendra Neupane ${ }^{1}$ \\ 'Department of Surgery, Bharatpur Hospital, Bharatpur, Chitwan, Nepal, ${ }^{2}$ Department of Anaesthesiology, Bharatpur \\ Hospital, Bharatpur, Chitwan, Nepal.
}

\begin{abstract}
Introduction: Endoscopic retrograde cholangiopancreatography is one of the most frequently used treatment modality for various pancreatobiliary problems. Frequent complications of endoscopic retrograde cholangiopancreatography include pancreatitis, cholangitis, hemorrhage and perforation. This study was done to see the prevalence of post endoscopic retrograde cholangiopancreatography pancreatitis in patient aggressively hydrated with Ringer's Lactate solution.
\end{abstract}

Methods: A descriptive cross sectional study was carried out on patient undergoing endoscopic retrograde cholangiopancreatography at Bharatpur Hospital from June 2018 to August 2020. Ethical clearance was taken from Institutional Review Committee Bharatpur Hospital (reference number 16/076/77). The convenient sampling method was applied. Data were collected and analyzed in statistical package for the social sciences version 16. Point estimate at $95 \%$ confidence interval was calculated along with frequency and proportion for binary data.

Results: Pain abdomen was assessed using Visual Analogue Scale and it was found that $8.1 \%$ of patients (15 patients) complained of pain abdomen with visual analogue scale $>3$. Serum amylase was sent only in those patients who complained of pain abdomen and only in three patients $(1.6 \%)$ serum amylase was increased more than 3 times the upper limit of normal value suggestive of pancreatitis. All three patients who had pancreatitis had precut sphincterotomy.

Conclusions: In this study we found that incidence of pancreatitis slumped after aggressive hydration with Ringer's lactate solution and adjunct use of other prophylactic measures for prevention of post endoscopic retrograde cholangiopancreatography pancreatitis might yield further better results.

Keywords: endoscopic retrograde cholangiopancreatography; pancreatitis; ringer's lactate.

\section{INTRODUCTION}

Post Endoscopic Retrograde Cholangiopancreatography Pancreatitis (PEP) is the most common complication of Endoscopic Retrograde Cholangiopancreatography (ERCP). It ranges from $2 \%-10 \%$ and upto $40 \%$ in high risk cases. ${ }^{1}$ Various procedural techniques and pharmacological interventions have been investigated.

Aggressive hydration with Ringer's lactate ( $R L)$ fluid has been found to have promising result. Anti-inflammatory effect of RL has two possible explanations. First, lactate in $\mathrm{RL}$ gets metabolized to bicarbonate in liver which results in lowering metabolic acidosis whereas, normal saline (NS) when given in large volumes produces dilutional hyperchloremic acidosis due to high sodium and chloride content. Besides, plasma bicarbonate concentration decreases as chloride concentration increases. Studies show acidosis enhances inflammation

Correspondence: Dr. Ashis Pun, Department of Surgery, Bharatpur Hospital, Bharatpur-10, Chitwan, Nepal. Email: ashis_pun@hotmail.com, Phone: +9779851094189. 
and necrosis in acute pancreatitis.Second, RL may directly decrease inflammatory response in these patients by preventing activation of nuclear factor kappa B (NF-KB) transcription factor involved in the inflammatory process. ${ }^{2,3}$

Therefore, this study was carried out to find out the incidence of PEP after aggressive hydration with $R L$ in patients undergoing ERCP.

\section{METHODS}

A descriptive cross sectional study was conducted in the Department of Surgery, Bharatpur Hospital from June 2018 to August 2020. All the procedures were performed by same endoscopic surgeon in the same operative setting. Ethical approval was taken from the institutional review committee (IRC) Bharatpur Hospital (reference number 16/076/77).

The sample size was calculated using the following formula,

Sample size $(n)=z^{2} p(1-p) /(e)^{2}$, where

$z=1.96$ at $95 \% \mathrm{Cl}$

$\mathrm{p}($ prevalence $)=50 \%$

e $($ precision $)=5 \%$

Sample size (SS) $=384$

Now using Prevalence formula for finite population, No of patients undergoing ERCP in last 15 months = 300 approx.

Thus corrected sample size will be

$$
1+\frac{n}{\text { Population }}
$$

Where, $n=384$

$$
\text { Population }=300
$$

Corrected Sample size becomes 169 and adding $10 \%$ drop outs, sample size is estimated to be 186 .

Patients were aggressively hydrated with ringer lactate solution $(3 \mathrm{ml} / \mathrm{kg} / \mathrm{hr}$ ) during procedure, $20 \mathrm{ml} / \mathrm{kg}$ bolus immediately after procedure, and $3 \mathrm{ml} / \mathrm{kg} / \mathrm{hr}$ for 8 hours post procedure. ${ }^{4,5}$ Patient at risk of fluid overload were excluded from the study. Serum amylase $>3$ times the upper limit of normal was defined as PEP. Serum amylase was only sent if patient complain of pain (visual analogue score $>3$ ) persisting more than 8 hours. ${ }^{6}$ Injection diclofenac $75 \mathrm{mg}$ intramuscular was given during procedure. Only guidewire cannulation technique was used. Five French (Fr.) pancreatic duct (PD) stent was placed if PD cannulated $>3$ times.
Inclusion criteria: All patients undergoing ERCP with American Society of Anesthesiologist Physical Status (ASA- PS) I and II, with at least one risk factor for pancreatitis which may be procedure related or patient factor were included.

\section{Exclusion criteria:}

$\begin{array}{ll}- & \text { Acute pancreatitis } \\ - & \text { Congestive heart failure } \\ \text { - } & \text { Respiratory insufficiency } \\ \text { - } & \text { Severe liver disease } \\ \text { - } & \text { Hypo or hypernatremia }\end{array}$

Data analysis was done in the statistical package for the social sciences (SPSS) version 16. Point estimate at $95 \%$ confidence interval was calculated along with frequency and proportion for binary data.

\section{RESULTS}

A total of 186 patients undergoing ERCP were enrolled in this study. Each patient had a minimum risk factor for pancreatitis. During the post operative period, pain abdomen was assessed using Visual analogue Scale (VAS) and it was found that 15 patients $(8.1 \%, \mathrm{C} .1$ $95 \%$ patients) complained of pain abdomen with VAS > 3. Serum amylase was sent only in those patients who complained of pain abdomen and only in three patients $(1.6 \%$, C.I $95 \%)$ serum amylase was increased more than 3 times the upper limit of normal value suggestive of pancreatitis.

Of these 186 patients, 55 patients $(29.6 \%)$ were male and 131 patients $(70.4 \%)$ were female. Similarly, 23 patients $(12.4 \%)$ were American Society of Anaesthesiologist- physical status (ASA-PS) I and 163 patients $(87.6 \%)$ were ASA-PS II.

During the procedure, ease of cannulation into ampulla of vater was assessed and it was found that in 123 patients $(66.1 \%)$, cannulation was easy. However, 63 patients $(33.9 \%)$ had difficult cannulation. Similarly, precut sphincterotomy, pancreatic duct cannulation, and continuous radial expansion were performed in these patients as shown (Table 1 ).

\begin{tabular}{|lll|}
\hline Table 1. Procedure & Performed. \\
\hline Procedure & $\begin{array}{l}\text { Performed n } \\
(\%)\end{array}$ & $\begin{array}{l}\text { Not performed } \\
\mathrm{n}(\%)\end{array}$ \\
$\begin{array}{l}\text { Precut } \\
\text { Sphincterotomy }\end{array}$ & $46(24.7 \%)$ & $140(75.3 \%)$ \\
$\begin{array}{l}\text { Pancreatic Duct } \\
\text { Cannulation }\end{array}$ & $18(9.7 \%)$ & $168(90.3 \%)$
\end{tabular}


Pun et al. Ringer's Lactate Hydration and Incidence of Post ERCP Pancreatitis: A Descriptive Cross-sectional Study.

Continuous radial expansion $29(15.6 \%)$ $157(84.4 \%)$

Mean age of patients who had pain abdomen was $61 \pm 15.847$ years and mean age of patient who did not have pain abdomen was $51.09 \pm 15.938$ years. However, mean age of patients with serum amylase raised more than 3 times the upper limit of normal was $38.67 \pm 17.786$ years

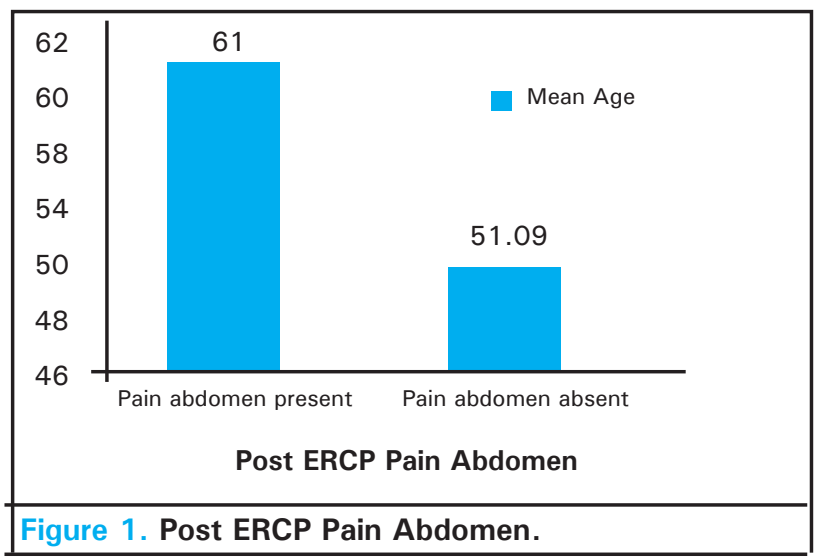

Similarly, post ERCP pain abdomen was significantly higher in patient with difficult cannulation compared to easy cannulation. Thirteen patients with difficult cannulation had pain abdomen compared to two patients with easy cannulation. All three patients who had pancreatitis (pain abdomen with increased serum amylase $>3$ times) had difficult cannulation while none patient with easy cannulation had pancreatitis.

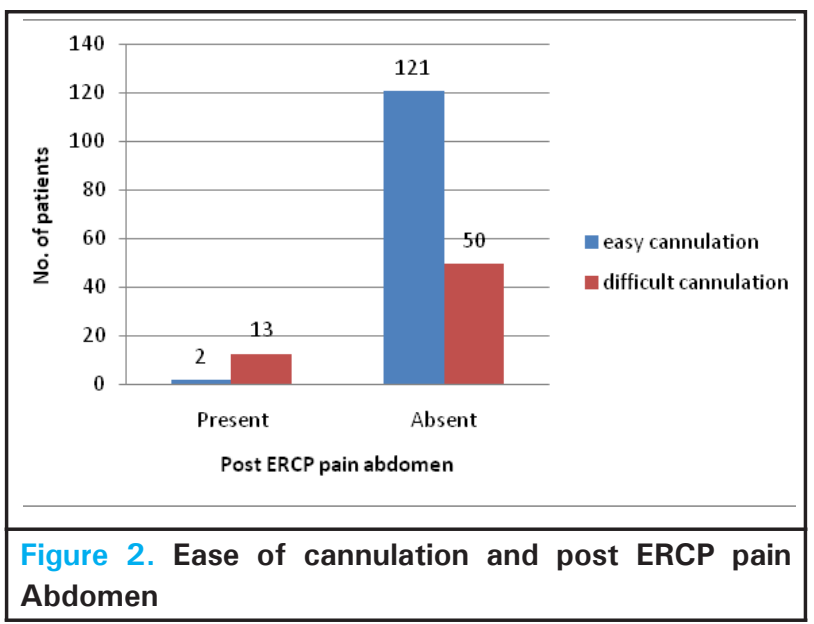

Incidence of post ERCP pain abdomen in patients who had precut sphincterotomy, pancreatic duct cannulation and continuous radial expansion was as follows (Table 2).

\begin{tabular}{|c|c|c|c|}
\hline & & $\begin{array}{l}\text { Pain } \\
\text { abdomen } \\
\text { Present }\end{array}$ & $\begin{array}{l}\text { Pain } \\
\text { Abdomen } \\
\text { Absent }\end{array}$ \\
\hline \multirow{2}{*}{$\begin{array}{l}\text { Precut } \\
\text { sphincterotomy }\end{array}$} & Performed & 11 & 35 \\
\hline & $\begin{array}{l}\text { Not } \\
\text { performed }\end{array}$ & 4 & 136 \\
\hline \multirow{2}{*}{$\begin{array}{l}\text { Pancreatic Duct } \\
\text { cannulation }\end{array}$} & Performed & 0 & 18 \\
\hline & $\begin{array}{l}\text { Not } \\
\text { Performed }\end{array}$ & 15 & 153 \\
\hline \multirow{2}{*}{$\begin{array}{l}\text { Continuous } \\
\text { radial } \\
\text { expansion }\end{array}$} & Performed & 2 & 27 \\
\hline & $\begin{array}{l}\text { Not } \\
\text { Performed }\end{array}$ & 13 & 144 \\
\hline
\end{tabular}

Similarly, all three patients who had pancreatitis had precut sphincterotomy. None of the patient who had undergone pancreatic duct stenting and continuous radial expansion developed pancreatitis.

\section{DISCUSSION}

Pancreatitis is the most frequent complication following ERCP attributed upto $40 \%$ in high risk cases. Various methods and techniques are studied and implicated for the prevention of pancreatitis. Guidewire technique of common bile duct (CBD) cannulation significantly lowered the incidence of PEP compared with the contrast-assisted method (RR 0.51; $95 \% \mathrm{Cl}, 0.32-$ $0.82) .4,5$. Recent meta-analyses calculated an odds ratio of 0.44 for rectal non-steroidal anti-inflammatory drugs (NSAIDs) and 0.35 for pancreatic duct (PD) stents. ${ }^{7-10}$

However, controversy exists on how PEP should be defined. Most commonly Cotton, et.al and revised Atlanta consensus of acute pancreatitis are widely accepted.Freeman et al reported that the risk factors for post-ERCP pancreatitis were both patient-related factors (i.e. female sex, young age, suspected sphincter of oddi dysfunction) and procedure-related factors (i.e. difficult cannulation, pancreatic duct injection, and precut sphincterotomy). ${ }^{11}$ In their study, the multivariate analyses of independent risk factors for post-ERCP pancreatitis demonstrated statistical association with cannulation difficulty (OR, 3.9; $95 \% \mathrm{Cl}, 1.7-8.6)$, dilation of an intact biliary sphincter (OR, 3.9; $95 \% \mathrm{Cl}$, 1.5-9.9), and non-use of vigorous hydration (OR, 2.4; $95 \% \mathrm{Cl}, 1.1-5.2) .{ }^{11}$

One of the methods for reducing incidence of pancreatitis is early vigorous hydration. The rationale behind vigorous hydration is to resolve hypovolemia so that perfusion is adequate. But now choice of fluid is shifted toward Ringer's lactate solution because of more suitable acid base balance and its anti-inflammatory 
property. However, there is still no definite evidence towards use of $\mathrm{RL}$ but results are encouraging in favour of RL. ${ }^{2,12-14}$ Therefore, American Society of Gastroenterology (ASGE) and European Society of Gastroenterology (ESGE) also supports RL hydration in medically fit patients.

In a 62 patient pilot study, aggressive hydration with ringer lactate solution demonstrated significant reduction in PEP compared to standard hydration (0\% vs 17\%; $P=0.016)$. Similarly, in a randomized, double-blinded, controlled study of 150 patients PEP was noted in $5.3 \%$ of patients receiving aggressive hydration compared with $22.7 \%$ receiving standard hydration $(P=.002) .{ }^{4}$ In a systemic review and metaanalysis done by $\mathrm{Wu} D$ and collegues on an efficacy of aggressive hydration with Ringer's Lactate published in 2017 showed lower incidence of pancreatitis after ERCP $(O R=0.29 ; 95 \%$ confidence interval $(\mathrm{Cl}), 0.16$ $0.53)$; a lower incidence of moderate to severe PEP (OR $=0.16 ; 95 \% \mathrm{Cl}, 0.03-0.96)$; lower incidence of hyperamylasemia $(\mathrm{OR}=0.38 ; 95 \% \mathrm{Cl}, 0.25-0.59)$; lower risk of pain $(\mathrm{OR}=0.17 ; 95 \% \mathrm{Cl}, 0.08-0.38)$; and a shorter duration of hospital stay (standardized mean difference $=-0.41 ; 95 \% \mathrm{Cl},-0.69$ to -0.14$).{ }^{15}$ Moreover, Zhang ZF, et al performed meta-analysis of randomized trial on aggressive Ringer's Lactate (RL) also found $\mathrm{RL}$ as an effective and safe therapy for prophylaxis of PEP. ${ }^{16}$

Park, et.al studied role of aggressive fluid therapy in three groups with aggressive $R L$, aggressive NS and normal hydration with RL. His study also showed significant difference in the PEP rate between the aggressive $\mathrm{RL}$ group $13.0 \%, 95 \%$ confidence interval [CI] $0.1 \%$ $5.9 \% ; 4 / 132)$, the aggressive NS group $(6.7 \%, 95$ $\% \mathrm{Cl} 2.5 \%-10.9 \% ; 9 / 134)$ and the standard $\mathrm{RL}$ group $(11.6 \%, 95 \% \mathrm{Cl} 6.1 \%-17.2 \% ; 15 / 129 ; \mathrm{P}=$
0.03). ${ }^{17}$ In our study also marked reduction in incidence of PEP was seen (1.6\% on aggressive Ringer's Lactate hydration protocol.

Besides for reduction of PEP rectal administration of NSAIDS is found to be effective in various study. ${ }^{18,19,20}$ Mok SRS et al. randomized, double blinded, placebocontrolled trial showed reduced incidence of PEP in ringer lactate plus rectal indomethacin versus normal saline plus placebo. ${ }^{21}$ In our study we have also included NSAIDs (diclofenac intramuscular) in all cases however, various studies support effectiveness of NSAIDs given only per rectal compared to other routes. But in our country rectal NSAIDS is not easily available so we don't practice giving prophylactic rectal NSAIDs for pancreatitis. In 2014, Ignasi Puigetal performed metaanalysis and also showed supporting evidence with rectal diclofenac or indomethacin given either before or after procedure but, there was no evidence to support oral or parenteral administration. ${ }^{22-24}$

\section{CONCLUSIONS}

Our study demonstrates that the introduction of selective and routine use of aggressive hydration with Ringer's lactate significantly reduces the incidence of pancreatitis. However, there are some confounding factors in our study like we had used guidewire cannulation technique, PD stents if $\mathrm{PD}$ cannulation $>3$ times and intramuscular diclofenac which might have also influenced in our result. Therefore, we conclude that aggressive hydration with $\mathrm{RL}$ reduces PEP and combining $\mathrm{RL}$ hydration with other methods for decreasing PEP may offer even better results.

\section{Conflict of Interest: None.}

\section{REFERENCES}

1. Adarsh M Thaker, Jeffrey D Mosko, Tyler M Berzin. Post-endoscopic retrograde cholangiopancreatography pancreatitis. Gastroenterol Rep (Oxf). 2015 Feb;3(1):32-40. [PubMed]

2. Iqbal U, Anwar H, Scribani M. Ringer's lactate versus normal saline in acute pancreatitis: A systematic review and meta-analysis. J Dig Dis. 2018 Jun;19(6):335-341. [PubMed]

3. Butterworth JF, Mackey DC, Wasnick JD. Fluid Management \& Blood Component Therapy. In: Morgan \& Mikhail's Clinical Anesthesiology. 5th ed. McGraw-Hill Education; 2013. p. 1164-6. [Full Text]

4. Chandrasekhara V, Khashab MA, Fasge VRM, Acosta RD, Mph DA, Bruining DH, et al. Adverse events associated with ERCP. Gastrointest Endosc. 2017;85(1):32-47. [PubMed]
5. Marek T, Baron TH, Hassan C, Testoni PA, Kapral C. Prophylaxis of post-ERCP pancreatitis : European Society of Gastrointestinal Endoscopy ( ESGE ) Guideline - Updated June 2014. Endoscopy. 2014;46(9):799-815. [P PubMed]

6. James B, Arthur Y, Kelvin Y, Christianne L, Nancy N, Loren L, et al. Aggressive hydration with lactated Ringer's solution reduces pancreatitis after endoscopic retrograde cholangiopancreatography. Clin Gastroenterol Hepatol. 2015;12(2):303-7.e1. [ubMed]

7. Choi J, Kim J, Lee U, Kim TH, Song IH. Vigorous Periprocedural Hydration With Lactated Ringer ' s Solution Reduces the Risk of Pancreatitis After Retrograde Cholangiopancreatography in Hospitalized Patients. Clin Gastroenterol Hepatol [Internet]. 2017;15(1):86-92.e1. 
Pun et al. Ringer's Lactate Hydration and Incidence of Post ERCP Pancreatitis: A Descriptive Cross-sectional Study.

\section{[PubMed]}

8. Choi J, Kim J, Lee U, Kim TH, Song IH. Vigorous Periprocedural Hydration With Lactated Ringer ' $s$ Solution Reduces the Risk of Pancreatitis After Retrograde Cholangiopancreatography in Hospitalized Patients. Clin Gastroenterol Hepatol. 2017;15(1):86-92.e1. [PubMed]

9. Sethi S, Sethi N, Wadhwa V, Garud S, Brown A. A Meta-Analysis on the Role of Rectal Diclofenac and Indomethacin in the Prevention of Post-Endoscopic Retrograde Cholangiopancreatography Pancreatitis. Pancreas. 2014;43(2):190-7. [ubMed]

10. Fan J, Qian J, Wang Y, Shi R, Zhao C, Fan J, et al. Updated meta-analysis of pancreatic stent placement in preventing post-endoscopic retrograde cholangiopancreatography pancreatitis. World J Gastroenterol. 2015;21(24):7577-83. [PubMed]

11. Smeets XJNM, Costa DW, Fockens P, Mulder CJJ, Timmer $\mathrm{R}$, Kievit $\mathrm{W}$, et al. Fluid hydration to prevent post-ERCP pancreatitis in average- to high-risk patients receiving prophylactic rectal NSAIDs ( FLUYT trial ): study protocol for a randomized controlled trial. Trials. 2018;19(1):207. [Full Text]

12. Freeman ML, Disario JA, Nelson DB, Fennerty MB, Lee JG, Bjorkman DJ, et al. Risk factors for post-ERCP pancreatitis: a prospective, multicenter study. Gastrointest Endosc. 1963;54(4):425-34. [PubMed]

13. Lipinski M, Rydzewska-rosolowska A, Rydzewski A, Rydzewska G. Fluid resuscitation in acute pancreatitis: Normal saline or lactated Ringer's solution? World J Gastroenterol. 2015;21(31):9367-72. [PubMed]

14. Wu BU, Hwang JQ, Gardner TH, Repas K, Delee R, Yu S, et al. Lactated Ringer' s Solution Reduces Systemic Inflammation Compared With Saline in Patients With Acute Pancreatitis. Clin Gastroenterol Hepatol. 2011;9(8):710-717.e1. [PubMed]

15. Elmunzer BJ. Aggressive Intravenous Fluid Resuscitation for Preventing Post-Endoscopic Retrograde Cholangiopancreatography Pancreatitis: Finally on the Right Track. Clin Gastroenterol Hepatol. 2014;12(2):308-10. [Full Text]

16. Wu D, Wan J, Xia L, Chen J, Jie C, Zhu Y, et al. The Efficiency of Aggressive Hydration With Lactated Ringer Solution for the Prevention of Post-ERCP Pancreatitis. J Clin Gastroenterol.

\section{7;51(8):e68-76. [PubMed]}

17. Zhang Z, Duan Z, Wang L, Zhao G, Deng W-G. Aggressive Hydration With Lactated Ringer Solution in Prevention of Postendoscopic Retrograde Cholangiopancreatography Pancreatitis. J Clin Gastroenterol. 2017;51(3):e17-26. [PubMed]

18. Park C, Paik WH, Park ET, Shim CS, Lee TY, Kang C, et al. Aggressive intravenous hydration with lactated Ringer ' s solution for prevention of post-ERCP pancreatitis: a prospective randomized multicenter clinical trial Authors. Endoscopy. 2018;50(4):378-85. [uㅏbMed]

19. Yu L, Zhao K, Lu B. Review Article Use of NSAIDs via the Rectal Route for the Prevention of Pancreatitis after ERCP in All-Risk Patients: An Updated Meta-Analysis. Gastroenterol Res Pr. 2018;2018(1027530):1-10. [PubMed]

20. Okuno M, Shiroko J, Taguchi D, Yamaguchi K, Takada J. The Effectiveness of the Rectal Administration of Low-dose Diclofenac for the Prevention of Post-endoscopic Retrograde Cholangiopancreatography Pancreatitis. Intern Med. 2018;57(16):2289-94. [PubMed]

21. Park TY, Oh H, Fogel EL, Lehman GA. Prevention of post-endoscopic retrograde cholangiopancreatography pancreatitis with rectal non-steroidal anti-inflammatory drugs. Korean J Intern Med. 2020;35(3):535-43. [uuMed]

22. Mok SRS, Ho HC, Shah P, Patel M. Lactated Ringer' s solution in combination with rectal indomethacin for prevention of post-ERCP pancreatitis and readmission: a prospective randomized, double-blinded. Gastrointest Endosc. 2017;85(5):1005-13. [uㅏbMed]

23. Puig I, Calvet $\mathrm{X}$, Baylina $\mathrm{M}$, Isava A lvaro, Sort $\mathrm{P}$, Llao J, et al. How and When Should NSAIDs Be Used for Preventing Post-ERCP Pancreatitis? A Systematic Review and MetaAnalysis. PLoS One. 2014;9(3):e92922. [PubMed]

24. Sheiybani G, Brydon P, Toolan M, Linehan J, Farrant M, Colleypriest B. Does rectal diclofenac reduce post- ERCP pancreatitis? A district general hospital experience. Front Gastroenterol. 2018;9(1):73-7. [PubMed]

25. Lyu Y, Cheng Y, Wang B, Xu Y, Du W. What is impact of nonsteroidal anti- inflammatory drugs in the prevention of post-endoscopic retrograde cholangiopancreatography pancreatitis: a meta-analysis of randomized controlled trials. BMC Gastroenterol. 2018;18(1):1-16. [PubMed]

The Author(s) 2018.

This work is licensed under a Creative Commons Attribution 4.0 International License. The images or other third party material in this article are included in the article's Creative Commons license, unless indicated otherwise in the credit line; if the material is not included under the Creative Commons license, users will need to obtain permission from the license holder to reproduce the material. To view a copy of this license, visit http://creativecommons.org/licenses/by/4.0/ 